\title{
A case study of atmospheric boundary layer features during winter over a tropical inland station - Kharagpur $\left(22.32^{\circ} \mathrm{N}, 87.32^{\circ} \mathrm{E}\right)$
}

\author{
Denny P Alappattu*, P K Kunhikrishnan, Marina Aloysius and M Mohan \\ Space Physics Laboratory, Vikram Sarabhai Space Centre, Trivandrum 695 022, India. \\ *e-mail: dennyalp@gmail.com
}

The local weather and air quality over a region are greatly influenced by the atmospheric boundary layer $(\mathrm{ABL})$ structure and dynamics. ABL characteristics were measured using a tethered balloon-sonde system over Kharagpur $\left(22.32^{\circ} \mathrm{N}, 87.32^{\circ} \mathrm{E}, 40 \mathrm{~m}\right.$ above MSL), India, for the period 7 December 2004 to 30 December 2004, as a part of the Indian Space Research OrganizationGeosphere Biosphere Program (ISRO-GBP) Aerosol Land Campaign II. High-resolution data of pressure, temperature, humidity, wind speed and wind direction were archived along with surface layer measurements using an automatic weather station. This paper presents the features of ABL, like ABL depth and nocturnal boundary layer (NBL) depth. The sea surface winds from Quikscat over the oceanic regions near the experiment site were analyzed along with the NCEP/NCAR reanalysis winds over Kharagpur to estimate the convergence of wind, moisture and vorticity to understand the observed variations in wind speed and relative humidity, and also the increased aerosol concentrations. The variation of ventilation coefficient $(V C)$, a factor determining the air pollution potential over a region, is also discussed in detail.

\section{Introduction}

The frictional and thermal influence of earth's surface modifies the lowest few kilometers of atmosphere and this region of troposphere is known as the atmospheric boundary layer (ABL) (Oke 1978; Arya 2001). ABL is characterized by its turbulent nature due to which momentum, heat and moisture are transported in vertical. Most of the interactions between the atmosphere and biosphere take place within this layer. Moreover, ABL plays an important role in the radiation budget of the earth atmosphere system. Transports take place within the ABL balance the earth's radiant energy surplus and the atmosphere's deficit of which approximately $26 \%\left(88 \mathrm{Wm}^{-2}\right)$ are latent heat and $5 \%\left(17 \mathrm{Wm}^{-2}\right)$ sensible heat (Kiemle et al 1995). ABL depth over a region depends on several factors like incoming solar radiation, topography, surface roughness of the region as well as other surface forcings and thus the ABL depth exhibits high spatial and temporal variability. Furthermore, the vertical extent and concentration of atmospheric pollutants over a region are decided by the depth of the boundary layer, the degree of vertical mixing, and the strength of advection. Hence a combined effect of weak vertical mixing and low winds can cause the building up of pollutant concentration in the ABL. Over the Indian subcontinent, it is observed that ABL height is low during monsoon period and winter (Praveena and Kunhikrishnan 2004; Devara and Raj 1993). However during monsoon, due to the strong prevailing winds, pollutants get dispersed quickly and washed out by precipitation. In contrast to this, during winter, both winds and ABL depth are low and hence over Indian subcontinent most of the pollution hazards occur during winter.

Keywords. Atmospheric boundary layer; nocturnal boundary layer; virtual potential temperature; ventilation coefficient. 
The Indo-Gangetic Plain (IGP) encompasses a vast area from $21.75^{\circ} \mathrm{N}, 74.25^{\circ} \mathrm{E}$ to $31.0^{\circ} \mathrm{N}, 91.5^{\circ} \mathrm{E}$ and accounts for a substantial portion of the land area of Indian subcontinent. IGP experienced a high rate of increase of urbanization and the associated growth in industrial activities over the last decade. For instance, a number of coal mines and thermal power plants are situated towards the eastern part of the IGP. As a possible consequence, the air quality over the cities situated in the IGP is substantially less, which is reported by the central pollution control board (CPCB), India (http://www.cpcb.nic.in). Studies based on satellite observations showed a winter-time accumulation of pollutants over the IGP region (Girolamo et al 2004; Ramanathan and Ramana 2005). Similar observations using ground-based techniques were also reported (Mönkkonen et al 2004; Singh et al 2004; Dey et al 2005). This may be attributed to the increase of anthropogenic aerosol loading in the last few years. Recently, large number of researches have shown that the radiative forcing by aerosols has profound effects on the climate change over a region (for example, see Satheesh and Ramanathan 2000; Intergovernmental Panel on Climate Change (IPCC) report, 2001). In this context, the regions like IGP, where a large amount of anthropogenic aerosol loading takes place, is of significant interest as far as its climatic effects are concerned. The meteorological observations reported that colder winter with hazy/smoggy sky is a common occurrence over this region for the last few years. This haze prolongs throughout the winter and can be seen all over the Ganga basin. To understand this variability, the quantification of aerosol loading as well as their long-range transport is extremely important. Since it is the dynamics of the ABL, which directly influences the diurnal changes in the concentrations of aerosols over any region, coordinated measurements of $\mathrm{ABL}$ parameters as well as aerosol concentrations become imperative.

However, co-ordinated observations covering the vast continental landmass of India, comprising of the IGP have been sparse, even though there were some unique campaigns over the ocean regions surrounding the Indian subcontinent (for example, see Ramanathan et al 2001). In the past, the Monsoon Trough Boundary Layer Experiment (MONTBLEX-1990) investigated the atmospheric boundary layer processes in the monsoon trough area of northern India (Goel and Srivastava 1990). Parasnis and Morwal (1994) studied the thermodynamic features of the convective boundary layer using aerological observations at Calcutta, Bhubaneswar, New Delhi and Jodhpur obtained during MONTBLEX-90, and the mixed layer depths using SODAR observations over an inland station, Kharagpur were used to understand the saturation of mixed-layers after the onset phase of the monsoon. Murthy et al (1996) used the SODAR observations over Kharagpur to study the variation of the nocturnal boundary layer during monsoon period. Nonetheless, in the past there have been no in situ observations of ABL parameters during winter season over the IGP region. In view of this, Aerosol Land Campaign II (ALC-II) was conducted under Indian Space Research Organization - Geosphere Biosphere Program (ISRO-GBP) from 1-31 December 2004 over the IGP, especially to understand the winter-time accumulation of aerosols and the dynamics which governs it. Seven land stations were set up from Hissar $\left(29.17^{\circ} \mathrm{N}, 75.72^{\circ} \mathrm{E}\right)$ to Kharagpur $\left(22.32^{\circ} \mathrm{N}\right.$, $87.32^{\circ} \mathrm{E}$ ) along the Indo-Gangetic Plain (Tripathi et al 2006). During the ALC-II, Space Physics Laboratory set up instruments for aerosol and ABL measurements at the Indian Institute of Technology campus, Kharagpur. Even though the aerosol campaign started from December 1, 2004, the ABL measurements were made only from December 7, 2004. Since Kharagpur is located close to the Bay of Bengal (BoB), ABL dynamics therein plays a major role in transporting aerosols to the oceanic region. This paper reports the observations of ABL features and its dynamics over Kharagpur and the day-to-day variability of ventilation coefficient $(V C)$, which is a measure of the ability of the ABL to disperse pollutants.

\section{Experiment site and database}

The experiment site is located $\sim 80 \mathrm{~km}$ away from BoB coast (figure 1 ), and $40 \mathrm{~m}$ above mean sea level (MSL). The location is vegetated land and the terrain is flat. During the campaign, profiling of ABL parameters, viz., pressure, temperature, humidity, wind speed and wind direction were carried out using a tethersonde system (AIR, USA). This tethersonde system consists of an aerodynamically shaped balloon, meteorological payload, an electrical winch and tether line. The payload contains pressure, temperature, humidity and wind measuring sensors. Table 1 summarizes the range and the resolution of these balloon-borne sensors. The tethered balloon was raised and lowered using the electrical winch and ascending and descending rate of payload was controlled to get an average vertical resolution of $3 \mathrm{~m} .24$ days of soundings were realized over the experimental site with a total of 158 good soundings and a minimum of four flights per day. In addition to the ABL profiling using tethersonde, other sensors were also operated at $11 \mathrm{~m}$ above the surface for continuous measurements of temperature, wind and humidity. 


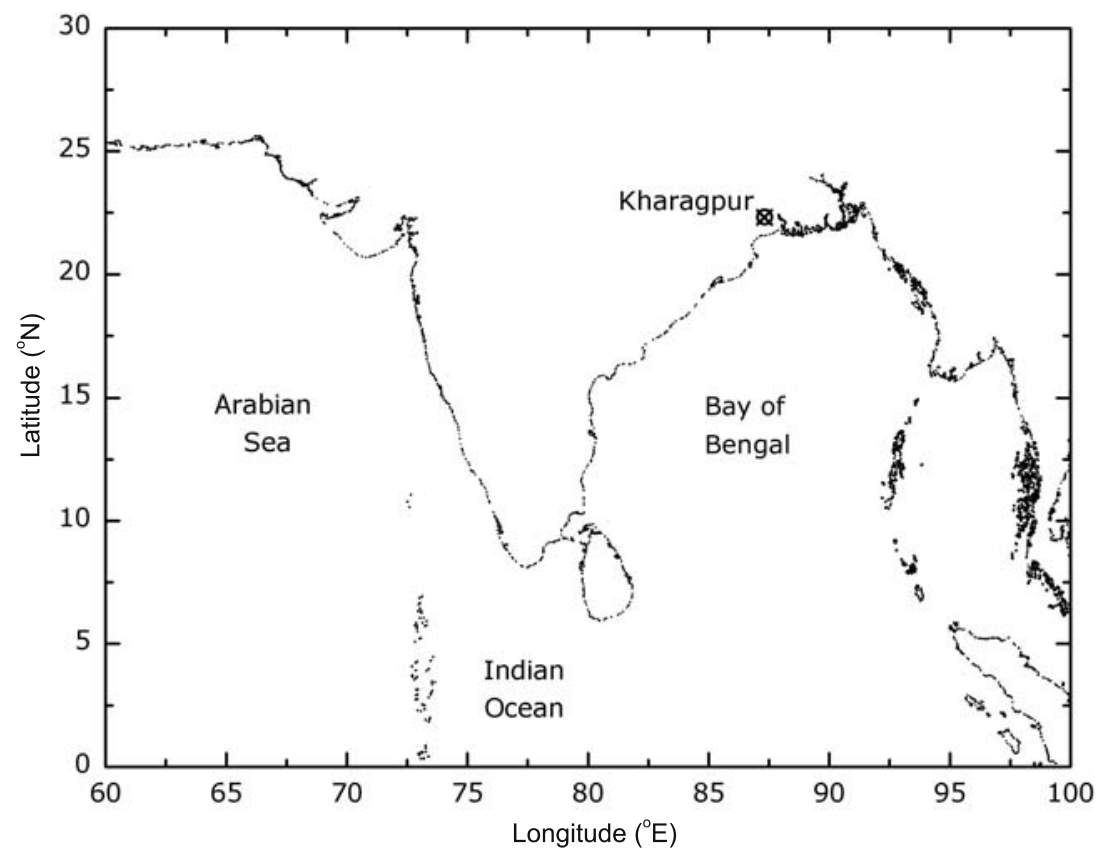

Figure 1. Map of Indian subcontinent showing the observational site - Kharagpur $\left(22.32^{\circ} \mathrm{N}, 87.32^{\circ} \mathrm{E}, 40 \mathrm{~m}\right.$ above $\left.\mathrm{MSL}\right)$.

Table 1. Range and resolution of various sensors used in the experiment.

\begin{tabular}{llll}
\hline & Sensor type & \multicolumn{1}{c}{ Range } & Resolution \\
\hline Temperature & $\begin{array}{l}\text { Wet and dry bulb } \\
\text { thermistors }\end{array}$ & $+50^{\circ}$ to $-70^{\circ} \mathrm{C}$ & $0.01^{\circ} \mathrm{C}$ \\
& Aneroid barometer & 1050 to $600 \mathrm{hPa}$ & $0.1 \mathrm{hPa}$ \\
Pressure & Cup anemometer & 0 to $20 \mathrm{~m} \mathrm{~s}^{-1}$ & $0.1 \mathrm{~m} \mathrm{~s}^{-1}$ \\
Wind speed & Magnetic compass & $2^{\circ}$ to $358^{\circ}$ & $1^{\circ}$ \\
Wind direction & &
\end{tabular}

However, during the campaign period, wind sensors mounted at $11 \mathrm{~m}$ did not function satisfactorily. The temperature and humidity sensors functioned well throughout the campaign period, and the data were archived at every 10 minutes interval.

\section{Prevailing meteorological conditions}

In general, sky was hazy on most of the days during the campaign period. Sky was overcast on Julian days (JD) $348,353,354,359$ and 360 . The temporal variation of surface temperature during the campaign period is shown in figure 2. Towards the end of the month, the entire northern India experienced severe cold wave condition, which significantly lowered the temperature. The minimum temperature recorded during the campaign was $10.8^{\circ} \mathrm{C}$ on JD 363 . The variations of pressure and wind speed at $20 \mathrm{~m}$ height from the surface are shown in figure 3(a) and (b) respectively. These values are pulled out from their altitude profiles obtained from the tethersonde ascents. Figure 3(c) shows the variation of relative humidity $(\mathrm{RH})$ measured at an altitude of $11 \mathrm{~m}$ from the surface. From figure 3(a), it can be seen that during the initial days of the campaign (i.e., up to JD 349) the pressure was relatively high (mean pressure was $1012 \mathrm{hPa}$ ), compared to the subsequent days (i.e., from JD 350-JD 359). The average pressure for the period JD 350 to JD 359 was found to be $1009 \mathrm{hPa}$ which is 2 to $3 \mathrm{hPa}$ less than that for the previous days. It can be seen that after JD 360, the pressure values were again high and comparable to the initial phase (i.e., up to JD 349) till the end of the campaign period. These three periods, i.e., JD 342-349, JD 350-359 and JD 360-365 are referred to as period I, period II and period III respectively in the subsequent discussion.

A similar trend was observed in the temporal variation of wind speed also. As seen from figure $3(\mathrm{~b})$, wind speed varied between 0.3 and $4.2 \mathrm{~ms}^{-1}$ during campaign period. Mean wind speeds during period I and period III were found to be $\sim 2 \mathrm{~ms}^{-1}$. The average wind speed during period II is seen to be lower than this (i.e., $1.2 \mathrm{~ms}^{-1}$ ). It may be noted that the mean wind speed for the entire observation period is only 


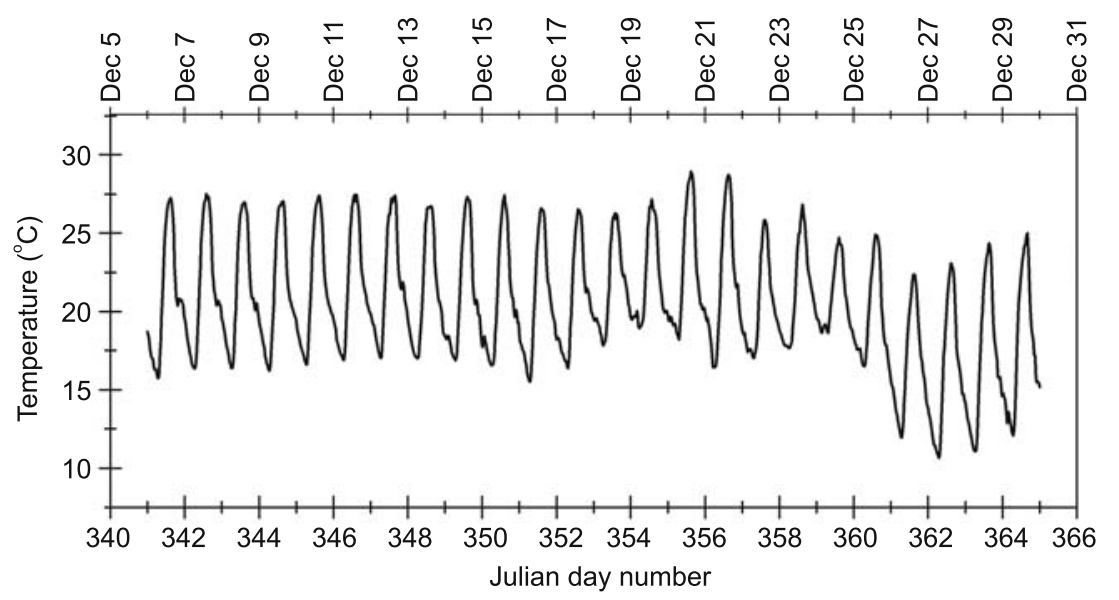

Figure 2. Variation of surface temperature over Kharagpur during the campaign period.

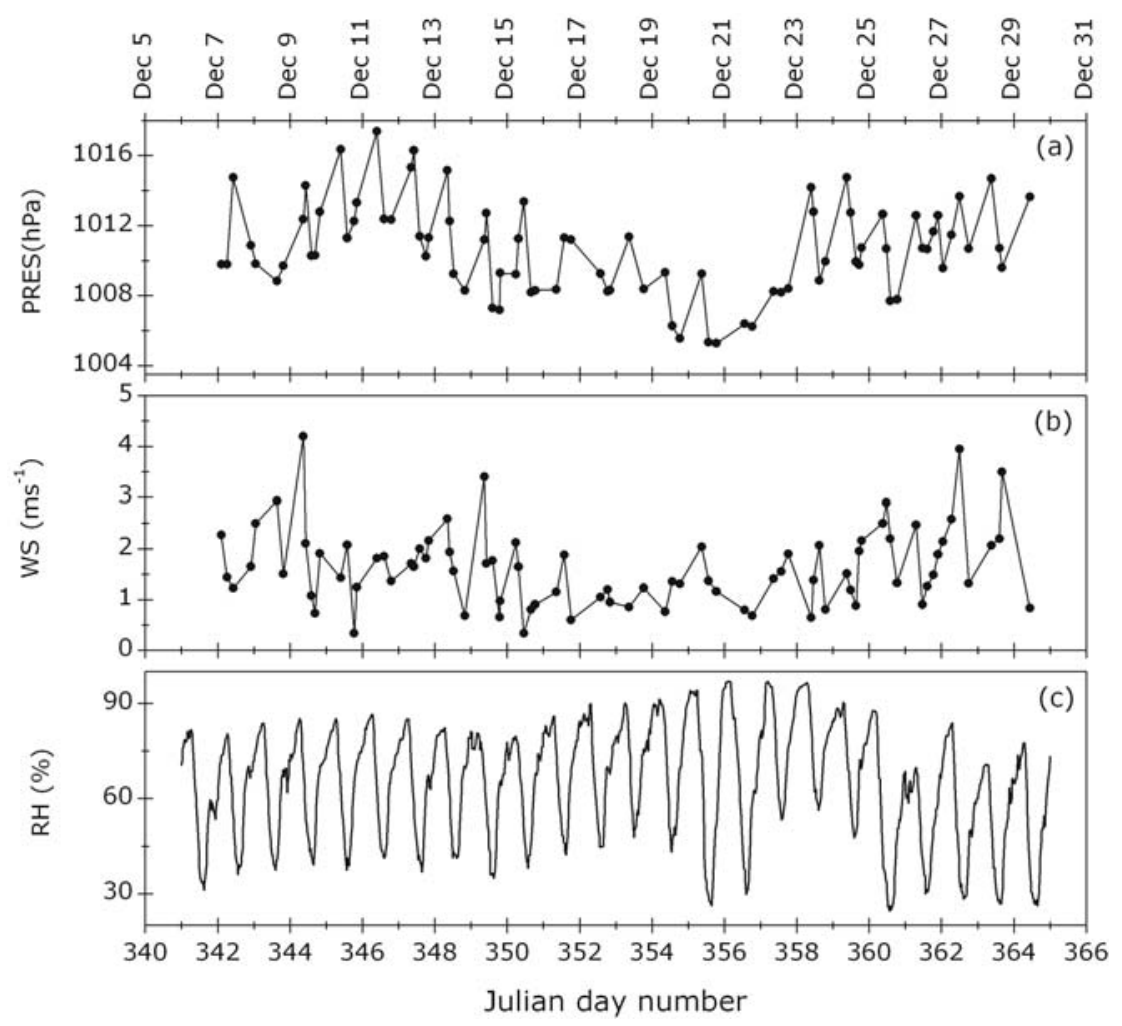

Figure 3. Variation of (a) pressure, (b) temperature and (c) relative humidity over Kharagpur during the campaign period.

$1.6 \mathrm{~ms}^{-1}$ at $20 \mathrm{~m}$, indicating the fact that in general winds were low during the campaign period, which is a characteristic feature of the winter season (Ramana et al 2004). In contrast to this, in case of $\mathrm{RH}$, the highest values were observed during period II; whereas, during periods I and III, RH values were comparatively lower (figure 3c). The average $\mathrm{RH}$ during period II was $71 \%$ which is higher by $7 \%$ and $14 \%$ than that of periods I and III respectively. The variation in temperature, pressure, humidity, wind speed and wind direction showed similar trends in other altitudes also (not illustrated). The high values of $\mathrm{RH}$ and low winds prevailed during period II are discussed in detail later, in the context of the observed aerosol concentrations and ABL characteristics.

\section{Result and discussion}

The altitude variation of pressure, temperature, humidity, wind speed and wind direction are 


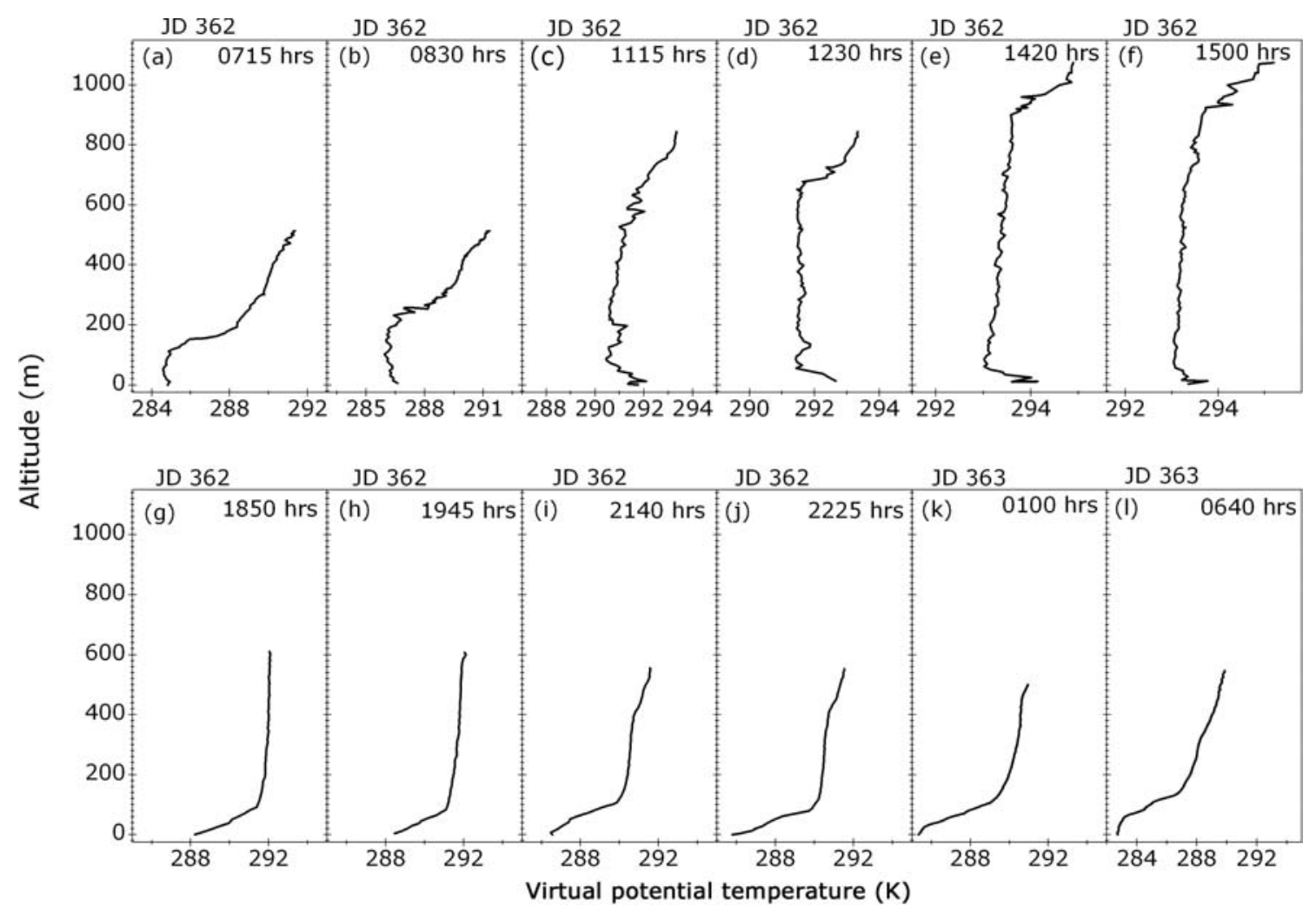

Figure 4. Altitude profiles of virtual potential temperature $\left(\theta_{v}\right)$ for different local times (observed on JD 362-JD 363).

obtained using the tethersonde system. The virtual potential temperature $\left(\theta_{v}\right)$ is estimated as follows (Stull 1991):

$$
\theta_{v}=\theta(1+0.61 r)
$$

where $\theta$ is the potential temperature $(\mathrm{K})$ and $r$ is the water vapour mixing ratio $\left(\mathrm{kg} \mathrm{kg}^{-1}\right)$. Within the mixed layer, $\theta_{v}$ is constant due to turbulent mixing of heat as well as moisture and hence does not vary more than $2 \mathrm{~K} \mathrm{~km}^{-1}$ (Parasnis and Morwal 1993). Unlike this, $\theta_{v}$ shows an abrupt change in magnitude above the mixed layer. The altitude where this sharp gradient occurs in $\theta_{v}$ is generally considered as the mixed layer height (Stull 1991; Satyanarayana et al 2001). Hence, the top of the mixed layer is often identified from the virtual potential temperature $\left(\theta_{v}\right)$ profiles (Garratt 1992).

Figure 4 shows the altitude profiles of virtual potential temperature from tethersonde soundings made on JD 362-363 at different local times (local time is shown at top-right corner of each panel). During early morning hours (i.e., figure $4 \mathrm{a}$ and $\mathrm{b}$ ) inversion in $\theta_{v}$ occurs at very low heights (around $150 \mathrm{~m}$ and $220 \mathrm{~m}$ respectively). As the day progresses, incoming solar radiation heats up the surface and the resulting convective activity increases the ABL depth. This is the cause of the elevated inversions $(650 \mathrm{~m}$ and $700 \mathrm{~m})$ seen in the soundings made at $11: 15 \mathrm{~h}$ and $12: 30 \mathrm{~h}$ (figure $4 \mathrm{c}$ and d) and the boundary layer height reaches its maximum of $\sim 900 \mathrm{~m}$ during the afternoon hours (figure 4e and f). Another feature that can be seen clearly in these profiles is the presence of surface layer (the lowest few meters of ABL where maximum gradient in $\theta_{v}$ occurs). In the soundings carried out at 11:15 h, 12:30 h, 14:20 h and 15:00 $\mathrm{h}$, the surface layer depth remains nearly the same $(\sim 90 \mathrm{~m})$. After sunset, the lowest layers of the atmosphere are characterized by an inversion, which is the result of cooling of the ground by the emission of long-wave radiation (Oke 1978) and the region of the boundary layer with this radiation inversion is known as the nocturnal boundary layer (NBL) or stable boundary layer (SBL). The $\theta_{v}$ profiles at $18: 50 \mathrm{~h}, 19: 45 \mathrm{~h}, 21: 40 \mathrm{~h}, 22: 25 \mathrm{~h}$ and 01:00 h (on JD 363) show well-developed NBL (figure $4 \mathrm{~g}-\mathrm{k}$ ). In all these profiles, $\theta_{v}$ increases up to the NBL top and remains almost constant above it. At night, the strong stability in the NBL reduces the vertical mixing and the pollutant dispersion becomes minimum. The low values of NBL depth can hence increase the concentration of pollutants near the earth's surface. The $\theta_{v}$ profiles of $06: 40 \mathrm{~h}$ (on JD 363, figure 4l) exhibits the development of very shallow mixed layer and this profile shows 


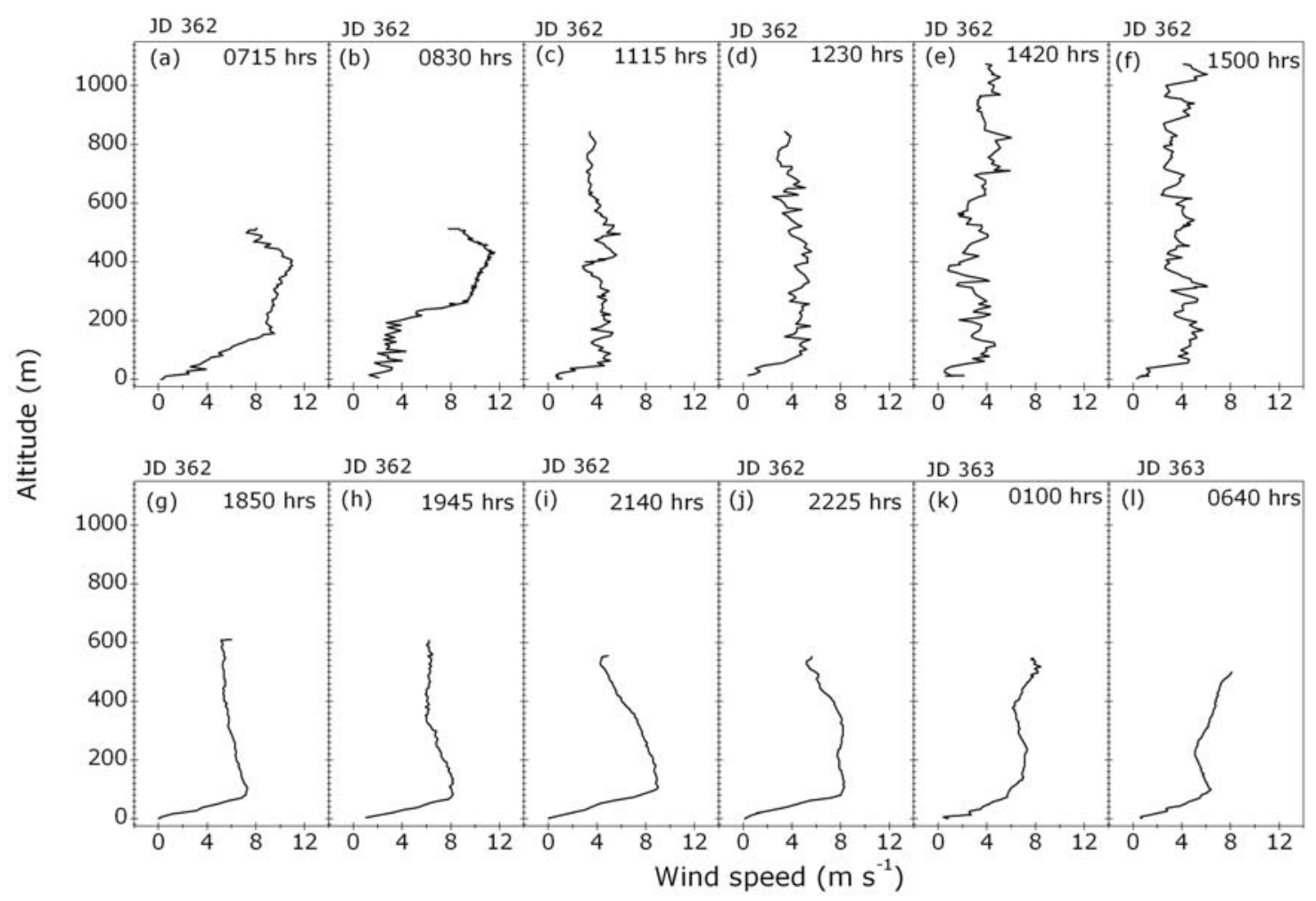

Figure 5. Altitude profiles of wind speed for different local times (observed on JD 362-JD 363).

the transition from the NBL to the daytime mixed layer.

Figure 5 shows the altitude profiles of wind speed corresponding to $\theta_{v}$ profiles shown in figure 4 . It is known that wind speed shows a gradual increase up to the top of surface layer, and in the daytime convective boundary layer $(\mathrm{CBL})$ wind speed does not vary much due to turbulent mixing. This kind of behaviour of wind speed can be clearly seen in all the daytime profiles. During night-time, ground-based inversion develops and wind speed peaks at the top of NBL. This is mainly because of acceleration due to the decoupling of the flow from the frictional effect. This behaviour can be seen from the night-time wind speed profiles. For instance, the profile at 19:45 h shows that the wind speed peaks at $\sim 90 \mathrm{~m}$ which is the top of SBL (figure 5h).

From the altitude profiles of $\theta_{v}$, ABL height was determined for each tethersonde flight. Figure 6 shows the variability in the daily maximum ABL height. The vertical bars show the ABL height determined from the $\theta_{v}$ profiles. The maximum ABL height observed was $980 \mathrm{~m}$ on JD 359 and minimum of $470 \mathrm{~m}$ was observed on JD 350. It can be seen that the ABL depths during period II were significantly lower than that during periods I and III. During period I, the mean ABL height was $811 \mathrm{~m}$. During periods II and III, the mean ABL depths were found to be $718 \mathrm{~m}$ and
$829 \mathrm{~m}$ respectively. The average ABL height during the period II is found to be lower compared to the other two periods. The mean value of the daily maximum ABL height is $776 \mathrm{~m}$ for the entire observation period. This is significantly lower than the mean noon-time ABL height for winter season $(\sim 1500 \mathrm{~m})$, observed over Gadanki $\left(13.5^{\circ} \mathrm{N} ; 79.2^{\circ} \mathrm{E}\right)$, another tropical inland station in India (Praveena and Kunhikrishnan 2004). However, it should be noted here that the surface features are significantly different for these two stations, Gandanki being located at $\sim 750 \mathrm{~m}$ above the mean sea level, the terrain is fairly complex.

Observations show that in daytime boundary layer, due to convective mixing, wind speed and direction remains more or less uniform. But top of the CBL is often associated with increased wind shear (Arya 2001). A study using the hourly averaged wind shear profiles derived from a lower atmosphere wind profiler (LAWP - Operating frequency: $1357.5 \mathrm{MHz}$ ) situated at Gadanki showed that in general, the ABL top coincides with the height of the maximum wind shear (Praveena 2003). To investigate this particular aspect, we have estimated the wind shear in the CBL using the altitude profiles of wind. The vertical wind shear is computed from the differences of the horizontal wind over the two levels, which are above and below the level considered. The wind shear at 


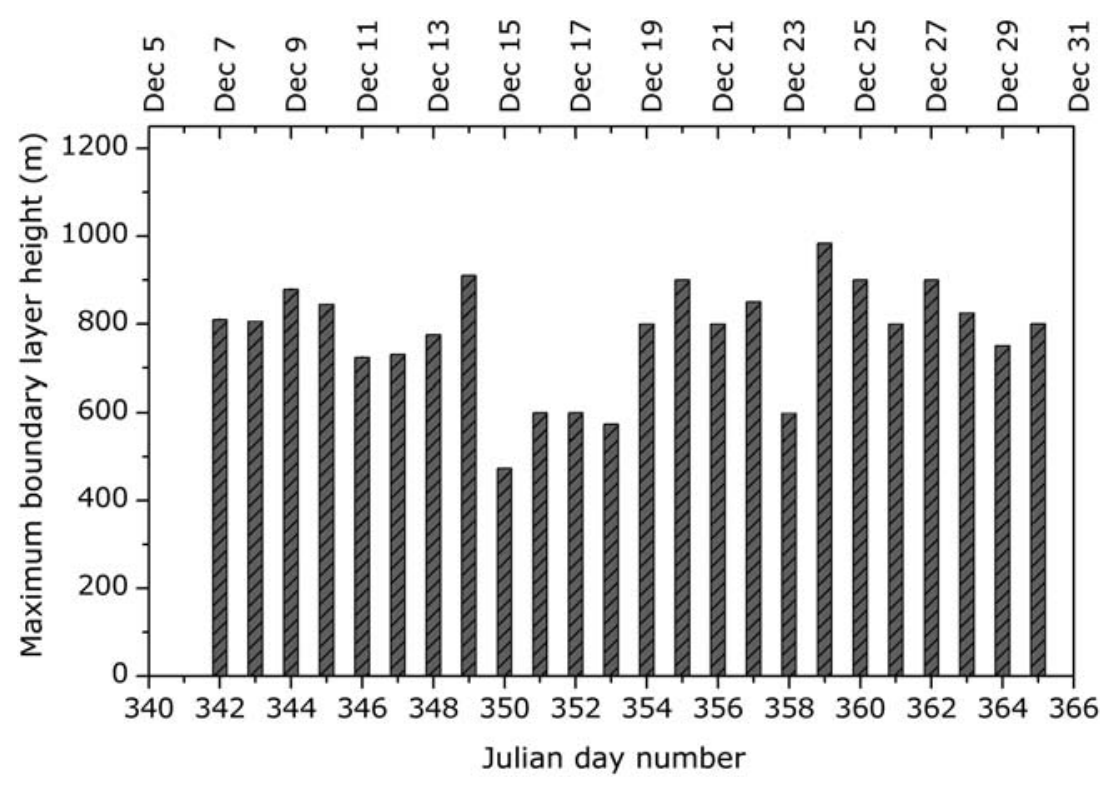

Figure 6. Day-to-day variability of daytime maximum ABL depth.

the altitude $z_{i}$ is given by:

$$
\left|\frac{d U}{d z}\right|_{z_{i}}=\left|\frac{U\left(z_{i}+d z\right)-U\left(z_{i}-d z\right)}{2 d z}\right|
$$

Figure 7(a) shows typical example of the profiles of virtual potential temperature (left panel) and wind shear (right panel). These profiles correspond to the tethersonde flight on JD 358 at 09:45 h. From the profile of virtual potential temperature the ABL depth can be identified as $320 \mathrm{~m}$. In the corresponding profile of wind shear, we can see that the vertical shear peaks at $340 \mathrm{~m}$, which is more or less close to the ABL depth obtained using virtual potential temperature. A scatter plot of $\mathrm{ABL}$ depth determined from virtual potential temperature and altitude of maximum wind shear is given in figure $7(\mathrm{~b})$. The wind speed data on days where a clear wind shear maximum is observed in the profile (similar to that shown in figure 7a, right panel) only are used for this analysis. A good correlation of 0.98 is obtained between the ABL depth delineated from virtual potential temperature and altitude of maximum wind shear, which shows that the wind shear maximum often occurs at the daytime ABL top.

Figure 8 shows the day-to-day variability observed in the maximum height of the groundbased inversions, identified from the altitude profiles of $\theta_{v}$, observed between 20:00 and 23:00 h. It can be seen that the NBL altitude varied from $41 \mathrm{~m}$ (on JD 348) to $125 \mathrm{~m}$ (on JD 359). During the first half of the campaign (from JD 342 to 353) NBL height was low (varied between $40 \mathrm{~m}$ and $66 \mathrm{~m})$ except for JDs $342(87 \mathrm{~m})$ and 343 $(112 \mathrm{~m})$. Again on JD 354, NBL depth was high $(105 \mathrm{~m})$, but during the next three days it was relatively low $(62 \mathrm{~m}$ to $70 \mathrm{~m})$. From JD 359 to JD 362, NBL depth was more than $100 \mathrm{~m}$ and afterwards NBL depth was less than $80 \mathrm{~m}$. The average NBL depth obtained for December 2004 is $\sim 75 \mathrm{~m}$, from tethersonde flights carried out between 20:00 and 23:00 h. It may be noted that this value is much lower than the average NBL depths reported by Murthy et al (1996) for July (324 m) and August $(296 \mathrm{~m})$ using the SODAR data obtained during the MONTBLEX-90.

These variations in the ABL depth as well as in the mean wind have significant ramifications in terms of the air quality over a particular region. Ventilation coefficient $(V C)$ is one of the parameters used to assess the air pollution potential over a region. It represents the rate at which the air within the convective boundary layer is transported. $V C$ is given by,

$$
V C=z_{i} \cdot U
$$

where $z_{i}$ is the mixed layer height and $U$ is the mean wind in the mixed layer. $V C$ is a direct measure of the ability of ABL to disperse pollutants, and a higher value of $V C$ indicates a more effective dispersion. Using the ABL depth and the corresponding wind speed obtained during different local times, the $V C$ values were computed for the entire campaign period. In general, $V C$ was low during the morning and evening hours but maximum during the early afternoon hours (not illustrated, see Nair et al 2007). Figure 9 shows 

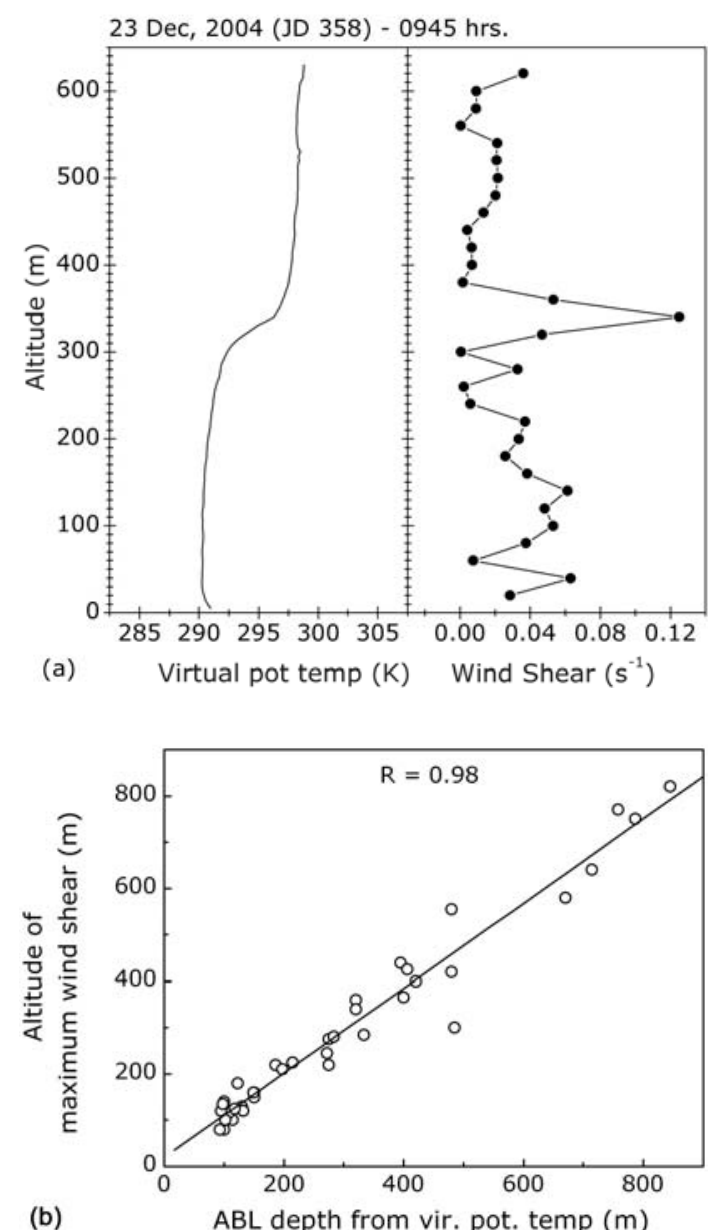

Figure 7. (a) Altitude profiles of virtual potential temperature $\left(\theta_{v}\right)$ and horizontal wind shear on JD 358 at $0945 \mathrm{~h}$ and (b) Scatter plot between ABL depths derived from virtual potential temperature profiles and the altitude of maximum wind shear.

the $V C$ estimated over Kharagpur during the campaign period, determined using the maximum $\mathrm{ABL}$ depth shown in figure 6 and the mean wind in ABL. It can be seen that $V C$ varied from 1024 to $5720 \mathrm{~m}^{2} \mathrm{~s}^{-1}$ with an average value of $2779 \mathrm{~m}^{2} \mathrm{~s}^{-1}$ during the campaign period. As clear from figure 9 , $V C$ also shows significant variation as that of wind speed and ABL height. During periods I and III, $V C$ values were much higher than that of period II. During period II mean value of $V C$ was $1626 \mathrm{~m}^{2} \mathrm{~s}^{-1}$ which was less compared to periods I and III by $1730 \mathrm{~m}^{2} \mathrm{~s}^{-1}$ and $2300 \mathrm{~m}^{2} \mathrm{~s}^{-1}$ respectively. This can be attributed to the lower winds and ABL depths prevailed during this period. Nair et al (2007) also reported that the dynamics of the local atmospheric boundary layer (ABL) as well as changes in local emissions strongly influence the diurnal variations of average mass concentrations of total aerosols and black carbon mass concentrations over IGP, both being inversely correlated with the mixed layer height and the $V C$.
Recently Niranjan et al (2006) reported the winter-time aerosol characteristics at Kharagpur during December 2004. Their measurements included the aerosol spectral optical depth at 5 wavelengths centered about $380,440,500,675$ and $870 \mathrm{~nm}$ using a Microtops Sun Photometer, near-surface aerosol mass concentrations using a 10 channel Quartz Crystal Microbalance (QCM) Impactor, etc. The variation of the ABL depths were derived from the micropulse lidar data between 18:00 and 19:00 $\mathrm{h}$ at the observation site. During the early part of the observation period, i.e., up to JD 348, the ABL depth was relatively higher compared to the later part of the month. They also observed an increase in the near-surface mass concentration during the period when ABL depths were low. Hence, they concluded that the boundary layer dynamics accounts for the day-today variability in the near-surface mass concentration of aerosols. They reported that 40 to $50 \%$ compression in the boundary layer has resulted in proportionate increase in the near-surface mass concentration from 100 to $200 \mathrm{mg} \mathrm{m}^{-3}$. They also reported that the day-to-day variability is nicely reproduced in the accumulation mode aerosols while the nucleation and coarse mode aerosols did not show the day-to-day variability. It was observed that the accumulation mode aerosol mass concentrations were significantly high during JD 349JD 354 (Niranjan et al 2006). It can be seen from figure 9 that the lowest $V C$ values were observed during this period. The low wind speed observed during this period (figure $3 \mathrm{~b}$ ) along with low ABL depths has caused this substantial reduction in $V C$. However, Niranjan et al (2006) have attributed the increase in aerosol concentrations entirely to the compression in the boundary layer depth. A close examination of the $V C$ variations (figure 9) and the variations in the accumulation mode aerosol mass concentrations (Niranjan et al 2006) shows that they corroborate very well. The $V C$ values again became high towards the end of December, but the aerosol observations by Niranjan et al (2006) were only up to JD 362.

Recently, Aloysius et al (2008) investigated the generation and transport of aerosols over a region comprising the Ganga basin $\left(20^{\circ}-27.5^{\circ} \mathrm{N}\right.$, $\left.75^{\circ}-87.5^{\circ} \mathrm{E}\right)$, where the ALC-II was carried out using the MODIS (Moderate Resolution Imaging Spectroradiometer) Level-3 aerosol optical depth (AOD) data and NCEP reanalysis winds. Their analysis showed that a main factor causing high aerosol concentration over the Ganga basin is wind convergence. Moreover, they have found that the aerosol optical depth over Kharagpur as obtained from MODIS showed high values from JD 350-356, which again corroborates with our low $V C$ observations. In view of these observations, we have first 


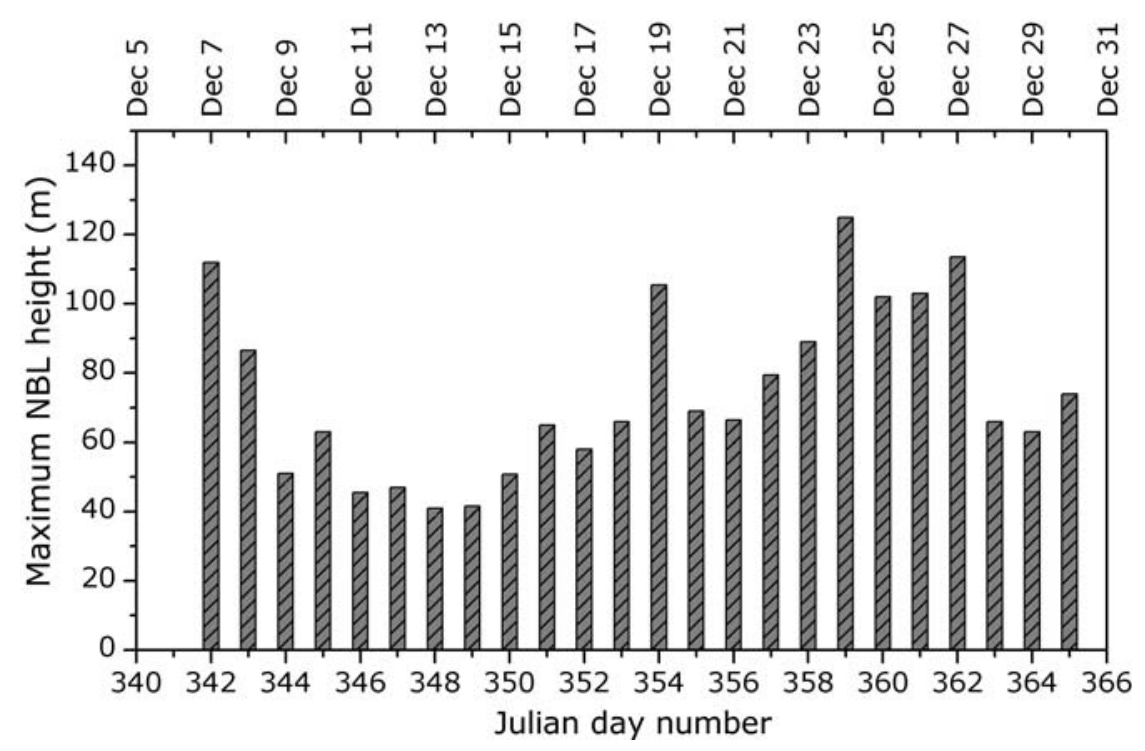

Figure 8. Day-to-day variability of maximum nocturnal boundary layer depth.

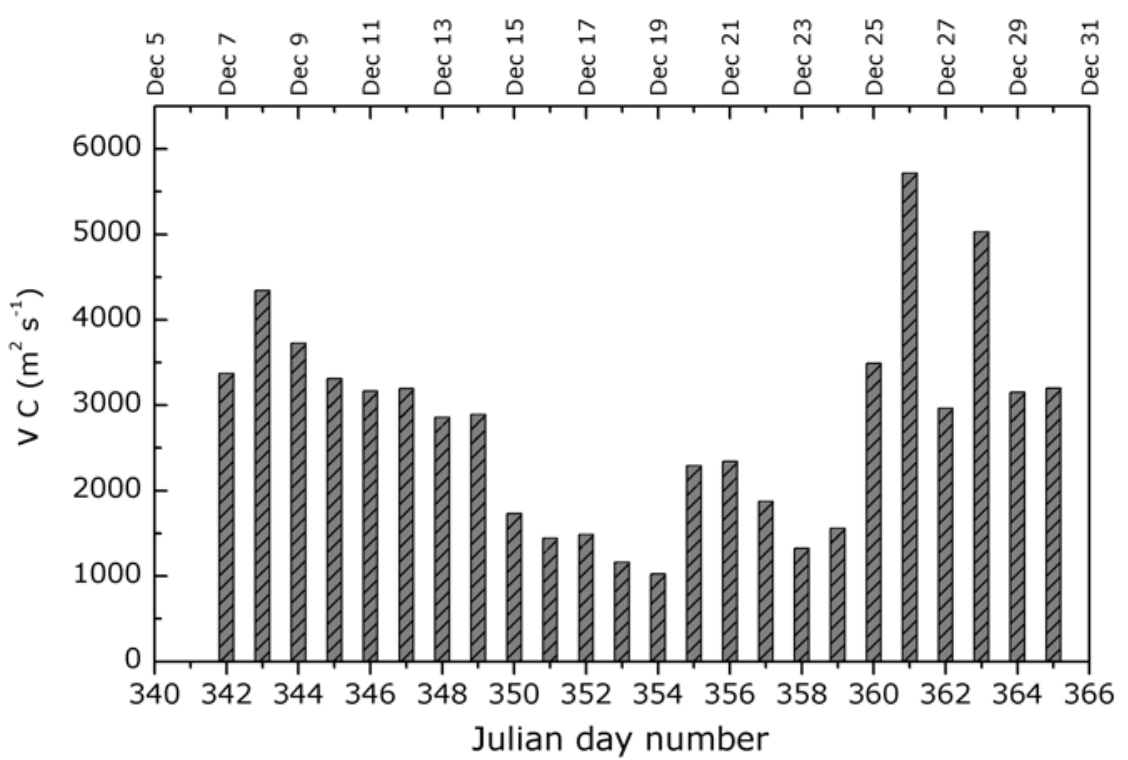

Figure 9. Day-to-day variability of ventilation coefficient $(V C)$ estimated from maximum ABL depth and mean wind.

looked into the reasons for the low wind speeds prevailed during the period II and then estimated the wind convergences over Kharagpur.

As mentioned earlier, $\mathrm{RH}$ values were significantly high during the period II, and this suggests that the winds might be of ocean origin, containing more humid air. Figure 10(a, b and c) shows the wind roses for the periods I, II and III respectively. Meteorological convention is followed for the construction of these plots and the radial axis represents the number of occurrences from a given direction. As seen from figure 10(a), wind was predominantly north-westerly during period I. But the behaviour of wind during the period II was quite different (figure 10b). During this period, even though the winds were seem to be north-westerly as well as north-easterly, on several occasions, winds were also seem to be blowing from east and southeast directions (i.e., between $60^{\circ}$ and $165^{\circ}$ ). Again from figure $10(\mathrm{c})$, it can be seen that during period III, winds were mostly confined between $0^{\circ}$ and $60^{\circ}$ and between $270^{\circ}$ and $330^{\circ}$. Analyzing the wind directions during these three periods along with the location of the Kharagpur (shown in figure 1), it can be seen that for the periods I and III, the winds were of land origin. Unlike this, during period II winds were of land as well as ocean origin and the increased $\mathrm{RH}$ values during this 

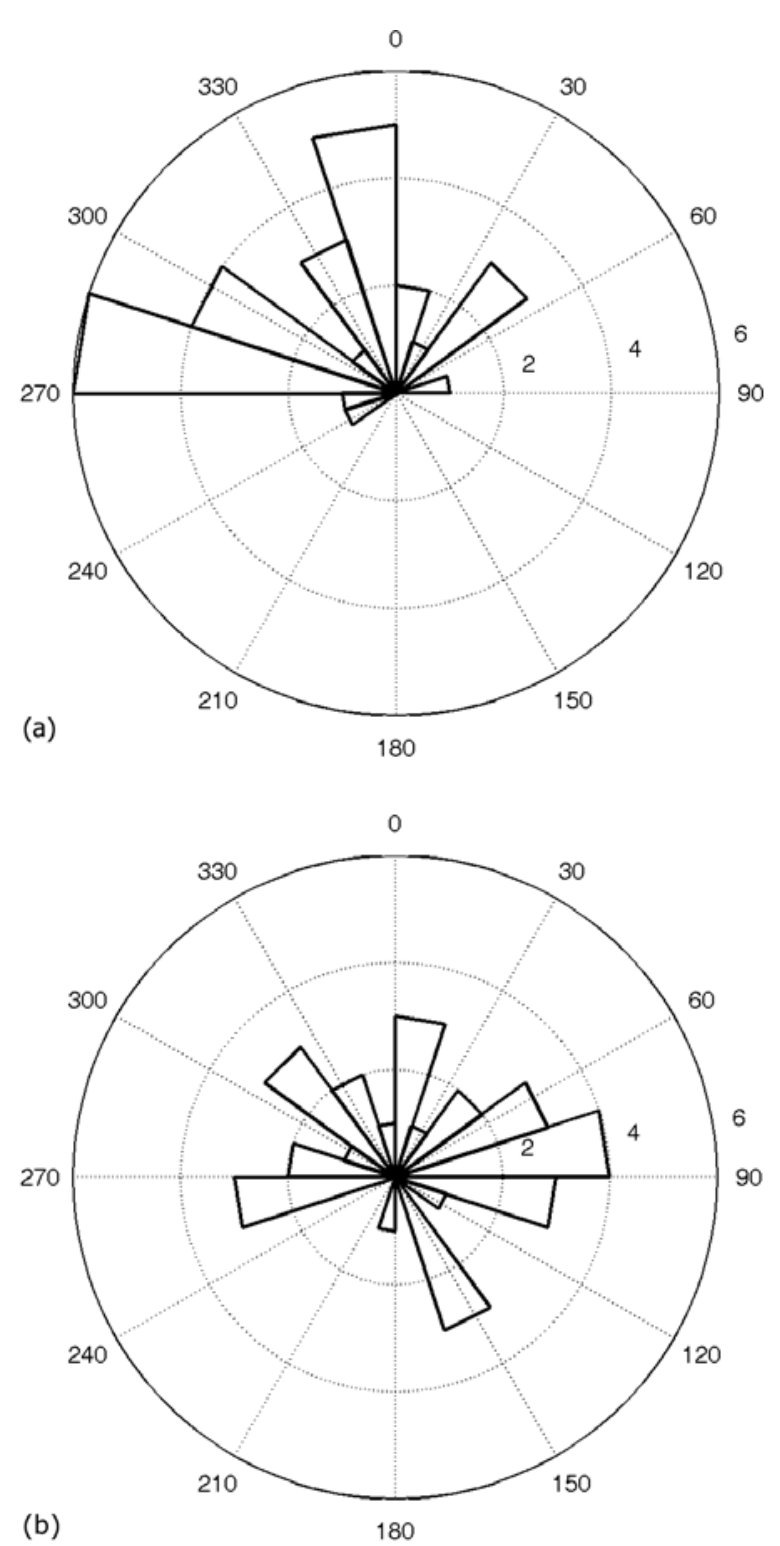

(b)

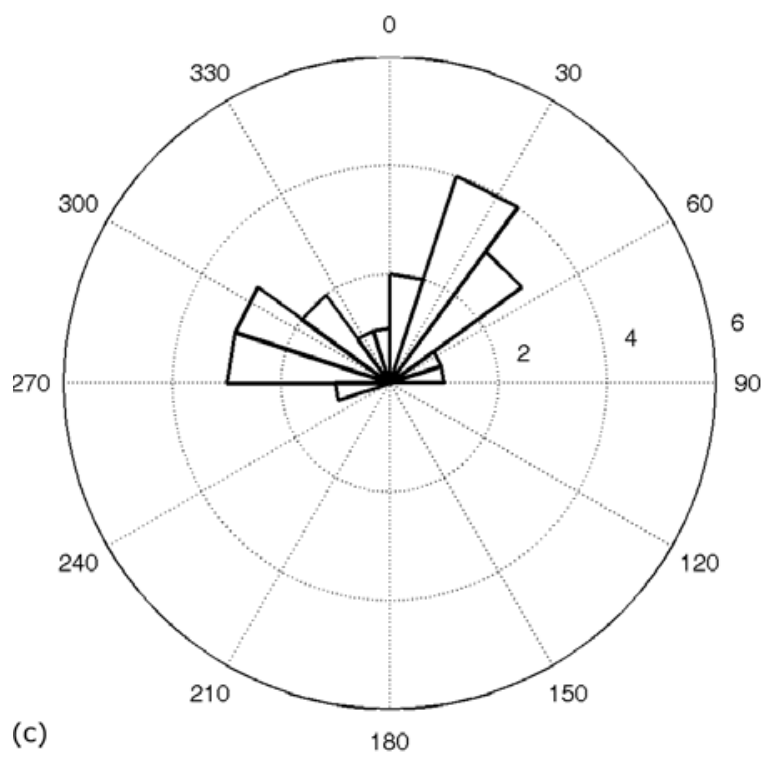

Figure 10. Wind roses for (a) period I (b) period II and (c) period III. period can be understood as an outcome of this. The winds which have blown from the BoB could retain the moisture content up to Kharagpur since it is only $80 \mathrm{~km}$ away from the BoB and the altitude above mean sea level is only $40 \mathrm{~m}$. It may be noted that the sea breeze activity over this location is also reported by Lohar et al (1994) using tower measurements. Climatologically, the wind is predominantly north-easterly during December over Indian subcontinent, and the winds blowing from east and southeast directions might be slowed down by these prevailing winds. This is the reason for the observed low wind speeds during period II. Since the tethersonde observations can give an idea about the wind speeds and directions over the experimental site alone, we have used satellite measurements to check the plausible wind reversals over the head BoB region during period II. For this we have used the Quikscat sea surface wind data at $10 \mathrm{~m}$ level.

Figure 11(a, b and c) shows the sea surface winds observed on three typical days corresponding to the three periods considered. Figure 11(a) shows the sea surface winds measured by Quikscat on JD 344. Over sea-side near Kharagpur, we can see that wind vectors pointed towards sea on this particular day. Similar behaviour is observed on other days during the period I (not illustrated). The winds in the above-mentioned region started changing its direction towards land from JD 350 onwards. This became more prominent from JD 352 to 358 and wind magnitudes were low. Figure 11(b) shows the wind vectors for the JD 354 (representing this period). There was again a significant change in the wind direction from JD 359 onwards. During this period flow became completely of land origin. Figure 11(c) shows a typical example corresponding to this period (for JD 362). Hence, the low RH values during periods I and III compared to that of period II could be attributed to this kind of a wind pattern, whereas the high $\mathrm{RH}$ values during period II could be due to the winds of the oceanic origin. As mentioned earlier, the pressure values over Kharagpur during this period were observed to be lower than those during periods I and III by about 2 to $3 \mathrm{hPa}$, which would have facilitated the advection of moist oceanic air to the land.

Further investigation of these observed variations in the meteorological conditions is done by looking into the synoptic conditions prevailed over the Kharagpur and adjoining oceanic region, using the NCEP/NCAR reanalysis daily mean winds and specific humidity data. The NCEP/NCAR winds were first compared with the observations to validate the NCEP data. The NCEP mean winds at $1000 \mathrm{hPa}$ level during the periods I, II and III were $2,1.3$ and $2.2 \mathrm{~ms}^{-1}$ respectively, and at $925 \mathrm{hPa}$, the mean wind speeds were $2.25,2.17$ and $3.73 \mathrm{~ms}^{-1}$ 
JD 344
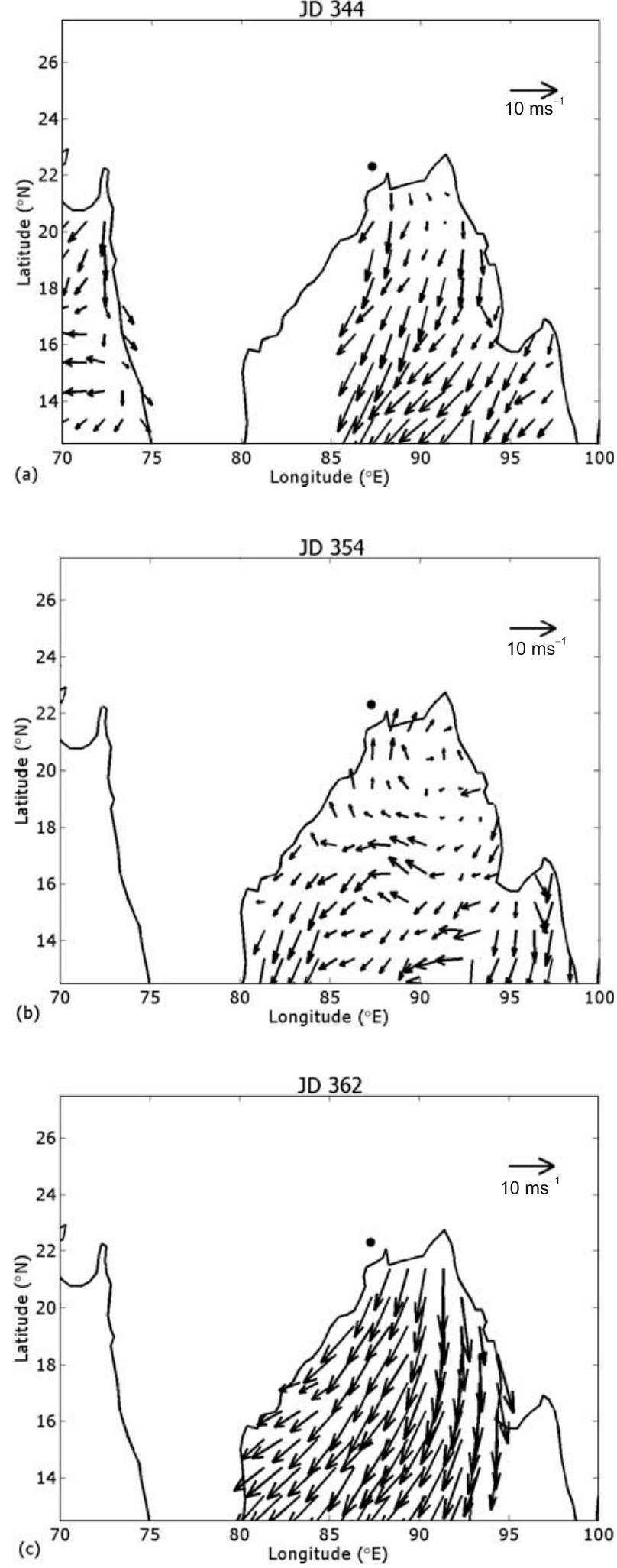

Figure 11. Quikscat derived sea surface wind for (a) JD 344 (b) JD 354 and (c) JD 362.

which are comparable to the observed values. Further, to quantify the variability in terms of the dynamical changes, we have estimated the wind vector convergence, vorticity and moisture flux

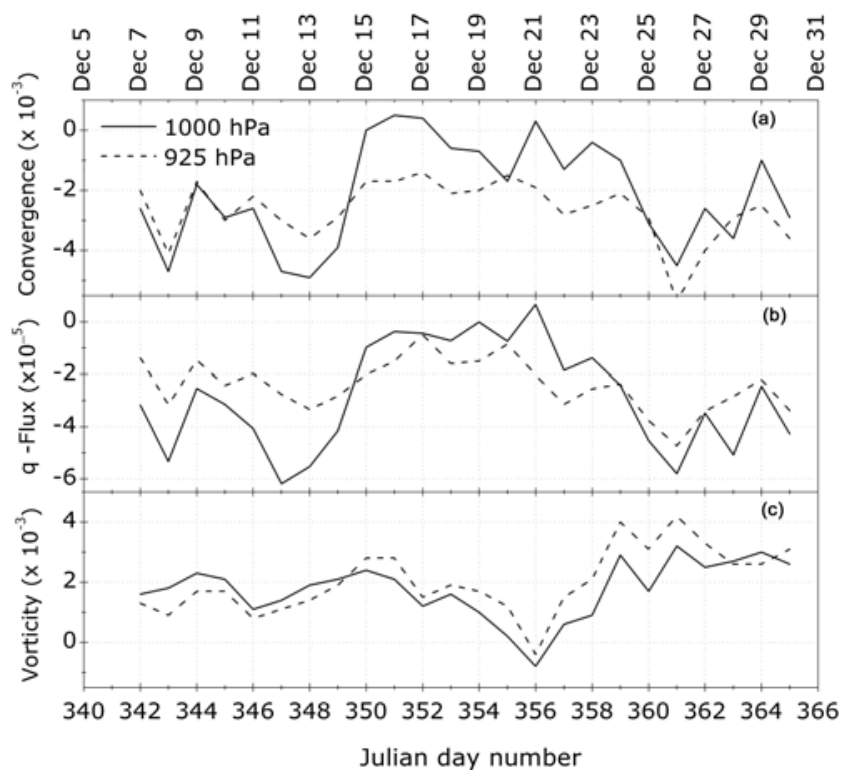

Figure 12. Temporal variation of (a) wind convergence, (b) moisture flux convergence and (c) vorticity over Kharagpur using NCEP reanalysis data at $1000 \mathrm{hPa}$ (solid lines) and $925 \mathrm{hPa}$ (dashed lines) levels.

convergence from the NCEP reanalysis data. The negative of the horizontal wind velocity divergence represents the fractional rate of increase of density following the motion of the air parcel (Holton 1992), given as:

$$
\frac{1}{\rho} \frac{d \rho}{d t}=-\nabla \cdot V
$$

The moisture flux convergence is obtained in a similar manner by taking the convergence of the product of wind speed and specific humidity. Similarly, the vorticity is negative in anticyclonic flow and this is associated with a high pressure region. It may be noted that the estimated values of convergence and vorticity represent a region of $2.5^{\circ} \times 2.5^{\circ}$ including Kharagpur. These estimates are obtained for two pressure levels, i.e., 1000 and $925 \mathrm{hPa}$.

Figure $12(\mathrm{a}, \mathrm{b}$ and $\mathrm{c})$ shows the variations of wind convergence, moisture flux convergence, and vorticity from JD 342 to JD 365 respectively. Figure 12(a) shows that wind is more divergent during periods I and III, whereas during period II wind divergence is practically absent. This trend can be seen at both levels. Figure 12(b) shows the moisture flux convergence for levels $1000 \mathrm{hPa}$ and $925 \mathrm{hPa}$. Initially during the period I and later during period III, moisture flux was more divergent in comparison to period II. Thus it can be inferred that, winds with oceanic origin tend to converge over this region during period II which would have caused increased $\mathrm{RH}$ over the 
region. As mentioned earlier, wind vorticity was also estimated for the campaign period. It should be noted that negative of the vorticity is plotted in figure 12(c) for the ease of interpretation. All days except JD 356, this parameter is positive which means that a weak anticyclonic circulation prevailed throughout this period. However, from JD 351 to 358 (period II) this anticyclonic circulation is much weaker with the low pressure values (see figure 3a). Vertical velocity $\left(\Omega\right.$ in $\mathrm{Pa} \mathrm{s}^{-1}$ ) over this region obtained from NCEP reanalysis also shows a similar trend (not illustrated). Thus it can be interpreted that the weakening of the anticyclonic circulation during period II lead to the formation of low pressure over the Kharagpur compared with period I and period III. From this analysis it can be clearly seen that the wind convergence was increased during period II, which corresponds to the period of low wind magnitudes, and low $V C$ values over Kharagpur. It must be mentioned here that, just because the winds were of oceanic origin, we cannot conclude that the increase in aerosol concentration is entirely from the oceanic region, because there was very little day-to-day variability of coarse-mode aerosols. As mentioned earlier, the winds blowing from east and southeast directions were slowed down by the prevailing winds, which are predominantly north-easterly during December over Indian subcontinent, and hence the wind speed was largely reduced during period II. This, together with the increased wind convergence, moisture flux convergence and the suppressed ABL depths caused an increased sustenance or accumulation of aerosols during period II compared to the other periods. Hence, these observations clearly reiterate the importance of local ABL dynamics in determining the pollutant concentrations over a region.

\section{Conclusions}

Boundary layer measurements were carried out over Kharagpur, a tropical inland station, during December 7-30, 2004. From the tethersondederived virtual potential temperature profiles, daytime and night-time ABL depths were obtained. An average daytime ABL depth of $776 \mathrm{~m}$ was observed over the experimental site, which is significantly lower than the corresponding values obtained over other inland stations in India. Similarly, an average NBL height of $\sim 75 \mathrm{~m}$ was obtained. The ventilation coefficient $(V C)$ was also determined for the observational period. It was found that $V C$ corresponding to the time of maximum ABL depth varied from 1024 to $5720 \mathrm{~m}^{2} \mathrm{~s}^{-1}$ with a mean value of $2779 \mathrm{~m}^{2} \mathrm{~s}^{-1}$. It is also found that during the period from JD 350 to 359 wind speed and pressure were low and RH was high compared to other days. Prevailing meteorological conditions showed that during this period winds were also of oceanic origin. This is confirmed from the sea surface winds from Quikscat. The wind and moisture flux convergence showed higher values from JD 350 to JD 359 as compared to other days. Similarly from the vorticity measurements, circulation over the area was found to be anticyclonic and this weakened during the period from JD 351 to 358 . VC also showed similar pattern as shown by wind speed, with significantly low values during the period from JD 350 to 359. Aerosol observations during this period (Niranjan et al 2006; Aloysius et al 2008) showed that their concentrations increased substantially during this period. The low values of $V C$, together with the increased wind convergence caused this enhancement, which has significant implications on the air quality over the region.

\section{Acknowledgements}

We are grateful to Dr A Jeyram, the Director, and to the scientific staff of RRSSC, Kharagpur for their concerted efforts which made the campaign a grand success. We are also grateful to Dr V Jayaraman, Program Director, ISROGBP program. We thank NASA ocean vector winds science team for providing Quikscat data through their website www.remss.com. We also acknowledge NOAA:CDC for providing the NCEP/NCAR reanalysis data through the website http://www.cdc.noaa.gov. One of the authors, Denny P Alappattu, gratefully acknowledges the financial assistance provided by the Indian Space Research Organization (ISRO) through research fellowship.

\section{References}

Arya P 2001 Micrometeorology; Academic Press.

Aloysius M, Mohan M, Parameswaran K, George S and Nair P R 2008 Aerosol Transport over the Gangetic Basin during ISRO-GBP Land Campaign-II; Ann. Geophys. 26 431-440.

Devara P C S and Earnest Raj P 1993 Lidar measurements of aerosols in the tropical atmosphere; Adv. Atmos. Sci. $10365-378$

Dey S, Tripathi S N, Singh R P and Holben B N 2005 Seasonal variability of the aerosol parameters over Kanpur, an urban site in the Indo-Gangetic basin; Adv. Space Res. 36 778-782.

Garrat J R 1992 The atmospheric boundary layer; Cambridge University Press, Cambridge.

Girolamo L D, Bond T C, Bramer D, Diner D J, Fettinger F, Kahn R A, Martonchik J V, Ramana M V, Ramnathan V and Rasch P J 2004 Analysis of multi-angle imaging spectroradiometer (MISR) aerosol optical depths over greater India during winter 2001-2004; Geophys. Res. Lett. 31 L23115, doi: 10.1029/2004GL021273. 
Goel M and Srivastava H N 1990 Monsoon trough boundary layer experiment (MONTBLEX); Bull. Amer. Meteorol. Soc. 71 1594-1600.

Holton J R 1992 An introduction to dynamic meteorology; Academic Press.

Kiemle C, Kastner M and Ehre E 1995 The convective boundary layer structure from lidar and radiosonde measurements during FEEDA '91 campaign; J. Atmos. Oceanic Tech. 12 771-782.

Lohar D, Pal B and Chakravarty B 1994 Sea breeze activity at an inland station Kharagpur (India) - A case study; Bound.-Layer Meteorol. 67 427-434.

Mönkkonen P, Uma R, Srinivasan D, Koponen I K, Lehtinen K E J, Hameri K, Suresh R, Sharma V P and Kulmala M 2004 Relationship and variations of aerosol number and PM10 mass concentrations in a highly polluted urban environment: New Delhi, India; Atmos. Environ. 38 425-433.

Murthy B S, Dharmaraj T and Vernekar K G 1996 Sodar observations of the nocturnal boundary layer at Kharagpur, India; Bound.-Layer Meteorol. 81 201-209.

Nair V S, Krishna Moorthy K, Alappattu D P, Kunhikrishnan P K, George S, Nair P R, Babu S S, Abish B, Satheesh S K, Tripathi S N, Niranjan K, Madhavan B L, Srikant V, Dutt C B S, Badarinath K V S and Reddy R R 2007 Wintertime aerosol characteristics over the Indo-Gangetic Plain (IGP): Impacts of local boundary layer processes and long-range transport; J. Geophys. Res. 112 D13205, doi: 10.1029/2006 JD008099.

Niranjan K, Sreekanth V, Madhavan B L and Krishna Moorthy K 2006 Wintertime aerosol characteristics at a north Indian site Kharagpur in the Indo-Gangetic plains located at the outflow region into Bay of Bengal; J. Geophys. Res. 111 D24209, doi:10.1029/2006JD007635.

Oke T R 1978 Boundary layer climates; Methuen \& Co. Ltd, NY.

Parasnis S S and Morwal S B 1993 Thermodyanamic structure of the atmospheric boundary layer over the Arabian Sea as revealed by MONSOON-77 data; Bound.-Layer Meteorol. 65 365-380.

Parasnis S S and Morwal S B 1994 A convectively-driven boundary layer in the monsoon trough; Bound.-Layer Meteorol. 71 197-204.

Praveena Krishnan 2003 Experimental and modeling studies of atmospheric boundary layer, PhD Thesis, University of Kerala, Trivandrum, Kerala, India.
Praveena K and Kunhikrishnan P K 2004 Temporal variations of ventilation coefficient at a tropical Indian station using UHF wind profiler; Curr. Sci. 86 447-450.

Ramana M V, Praveena K and Kunhikrishnan P K 2004 Surface boundary layer over a tropical inland region: seasonal features; Bound.-Layer Meteorol. 111 153-175.

Ramanathan V and Ramana M V 2005 Persistent, widespread, and strongly absorbing haze over the Himalayan foothills and the Indo-Gangetic plains; Pure Appl. Geophys. 162 1609-1626.

Ramanathan V, Crutzen P J, Lelieveld J, Mitra A P, Althausen D, Anderson J, Andreae M O, Cantrell W, Cass G R, Chung C E, Clarke A D, Coakley J A, Collins W D, Conant W C, Dulac F, Heintzenberg J, Heymsfield A J, Holben B, Howell S, Hudson, Jayaraman J, Kiehl J T, Krishnamurti T N, Lubin D, McFarquhar G, Novakov T, Ogren J A, Podgorny I A, Prather K, Priestley K, Prospero J M, Quinn P K, Rajeev K, Rasch P, Rupert S, Sadourny R, Satheesh S K, Shaw G E, Sheridan P and Valero1 F P J 2001 Indian Ocean Experiment: An integrated analysis of the climate forcing and effects of the great Indo-Asian haze; J. Geophys. Res. 106 28,371-28,398.

Satheesh S K and Ramanathan V 2000 Large differences in tropical aerosol forcing at the top of the atmosphere and Earth's surface; Nature 405 60-63.

Satyanarayana A N V, Mohanthy U C, Niyogy D S, Raman S, Lykossov V N, Warrior H and Sam N V 2001 A study on air-sea exchange processes in the ITCZ and non ITCZ regimes over Indian Ocean with INDOEX IFP-99 data; Curr. Sci. (Suppl.) 80 39-45.

Singh R P, Dey S, Tripathi S N, Tare V and Holben B N 2004 Variability of aerosol parameters over Kanpur, northern India; J. Geophys. Res. 109 D23206, doi: 10.1029/2004JD004966.

Stull S 1991 An introduction to boundary layer meteorology; Kluwer Academic Publishers.

Tripathi S N, Vinod Tare, Chinnam N, Srivastava A K, Sagnik Dey, Agarwal A, Kishore S, Lal R B, Manish Manar, Kanwade V P, Chauhan S S S, Sharma M, Reddy R R, Rama Gopal K, Narasimhulu K, Siva Sankara Reddy L, Shilpy Gupta and Shyam Lal 2006 Measurements of atmospheric parameters during Indian Space Research Organization Geosphere Biosphere Programme Land Campaign II at a typical location in the Ganga basin: 1. Physical and optical properties; J. Geophys. Res. 111 D23209, doi: 10.1029/2006JD007278. 